\title{
O Silenciamento de Marielle
}

Emely Braga RodRIGUES, Universidade Federal de Ouro Preto

O objetivo deste artigo é realizar uma narrativa empírico-contextual sobre o caso do assassinato da vereadora Marielle Franco a partir da análise de conteúdo de seus discursos descrevendo o contexto públicopolítico, as características e as relações entre as variáveis para chegar no teórico, utilizando o método jurídico-sociológico2. Considera-se que o campo político é historicamente masculino, branco, burguês e excludente das vozes das "subalternas" e a escolha do caso é justificada pela motivação do crime, vez que aquele assassinato significa o silenciamento de sua voz. O contexto de desenvolvimento da pesquisa se inicia no ano de 2017, no Brasil, ano em que a vereadora assumiu sua mandata. Analisa-se a contribuição do conceito de Fraser (paridade participativa) para a promoção de espaços mais dialógicos e democráticos a partir do reconhecimento das sujeitas subalternas como iguais participantes na ordem social.

PALAVRAS-CHAVE: Paridade participativa. Silenciamento vozes mulheres. Interseccionalidade. Injustiça social. Desigualdade gênero. 


\section{Introdução}

Esta pesquisa parte da concepção de gênero, apresentada por Nancy Fraser (2006), considerada como uma diferenciação social (híbrida), que "codifica padrões culturais onipresentes de interpretação e avaliação, que são fundamentais para a ordem de status em seu conjunto. Não só as mulheres, mas todos os grupos de status inferior correm o risco dessa feminilização, portanto, da depreciação"3 (FRASER, 2006, p. 29). Um exemplo de "padrão institucionalizado de valor cultural" exposto pela autora é o androcentrismo, que está presente no cotidiano, no direito, na família, na religião, na política, etc. e faz com que as mulheres sofram formas específicas de injustiça. Assim, a "dominação masculina" constrói habitus que se reproduzem na prática e,

pelo fato de o mundo limitado em que elas estão confinadas, o espaço do vilarejo, a casa, a linguagem, os utensílios, guardarem os mesmos apelos à ordem silenciosa, as mulheres não podem senão tornar-se o que elas são segundo a razão mítica, confirmando assim, e antes de mais nada a seus próprios olhos, que elas estão naturalmente destinadas ao baixo, ao torto, ao pequeno, ao mesquinho, ao fútil etc. (BOURDIEU, 2012 p. 41, destaque meu)

E esse habitus - que confina e que guarda apelo à ordem silenciosa em que a mulher é predestinada - opera de forma sistêmica se configurando como violência de gênero ligada às injustiças cultural, distributiva e política. Estes padrões culturais estruturam e fixam categorias/eixos de subordinação além do gênero, como a classe, a raça, o sexo, etc. que desvalorizam e/ou silenciam determinados grupos sociais também em razão de seu locus social. Isso é recorrente na história, em que, na maioria das vezes, só se sabe o lado contado pelo colonizador/ideologizador4 (homem, branco, rico e destemido).

As experiências desses grupos localizados socialmente de forma hierarquizada e não humanizada faz com que as produções intelectuais, saberes e vozes sejam tratadas de modo igualmente subalternizado, além das condições sociais os manterem num lugar silenciado estruturalmente. (RIBEIRO, 2017, paginação irregular)

Falar de silenciamento, ou de um lugar estruturalmente silenciado, é também falar de um "lugar de fala". Utilizo o conceito interpretado pela Djamila Ribeiro por compreender que este "lugar de fala” é mais amplo do que ter o direito a falar sobre determinada ótica ou experiência. Lugar de fala pressupõe um direito de existir. 
O falar não se restringe ao ato de emitir palavras, mas de poder existir. Pensamos lugar de fala como refutar a historiografia tradicional e a hierarquização de saberes consequente da hierarquia social. Quando falamos de direito à existência digna, à voz, estamos falando de locus social, de como esse lugar imposto dificulta a possibilidade de transcendência. Absolutamente não tem a ver com uma visão essencialista de que somente o negro pode falar sobre racismo, por exemplo. (RIBEIRO, 2017, paginação irregular)

O sentido de silenciamento a que refiro pode ser compreendido como um silêncio local, referindo-se também à censura (aquilo que é proibido de dizer, em certo contexto). Nesta dimensão política da linguagem, o silêncio serve como retórica tanto para a dominação (o opressor) como para o oprimido (resistência). "Aí entra toda a questão do 'tomar' a palavra, 'tirar' a palavra, obrigar a dizer, fazer calar, silenciar, etc. (...) E tem um campo fértil a ser observado: na relação entre índios e brancos, na fala sobre a reforma agrária, nos discursos sobre a mulher (...)" (ORLANDI, 2007, p. 29). Além disso, o silenciamento - como forma de violência de gênero - daquela "Outra" que é vista como uma inferior, está ligado à relação de poder, uma força simbólica5, violenta e invisível que, de forma pré-reflexiva, institui e sistematiza a relação entre domimante-dominada, fazendo-se reconhecerem como sujeito ou como subordinada, respectivamente. Então, o silêncio, o silenciamento causado pelo exercício do poder, apresenta um valor e um sentido, ele existe e pode ser observado, indiretamente, através de pistas, traços, mediante seus efeitos (retóricos e políticos) e processos de significação (ORLANDI, 2007, p. 42-46). Em virtude destes padrões culturais institucionalizados, de certa forma, todas as mulheres que são excluídas - exclusão no sentido mais amplo, de riquezas, de oportunidades, a interrupção, a invisibilidade, etc. - de participarem da esfera pública são silenciadas em razão de não possuírem o reconhecimento recíproco, consequentemente, não são capazes de participarem como iguais na sociedade (FRASER, 2002, p. 15-16).

\section{Desenvolvimento}

\subsection{Marielle e suas lutas}

Marielle Francisco da Silva, mais conhecida como Marielle Franco, nasceu em 27 de julho de 1979. Marielle foi mulher, negra, mãe, 
favelada e lésbica. Em 1998 cursou a primeira turma do pré-vestibular comunitário, na Favela da Maré, ano em que engravidou e entrou para as estatísticas de "mãe-solteira-adolescente", abandonando o curso préuniversitário. Nos anos 2000 começou a trabalhar nas instituições sociais com cultura e educação em sua comunidade.

Em 2006, conforme relato de Marcelo Freixo6, Marielle participou de sua campanha quando candidato à Deputado Estadual e foi escolhida pela comunidade a atuar junto a seu mandato, iniciado em 2007. Ela fazia parte da equipe de gabinete, atuou na Coordenação de Mandato e na Comissão de Direitos Humanos e Cidadania da Assembleia Legislativa do Estado do Rio de Janeiro (Alerj) ao lado de Freixo7, e, também, no relatório da CPI (Comissão Parlamentar de Inquérito)8 das milícias em 2008, como assessora parlamentar9. Graduada em sociologia pela PUC-Rio e mestra em Administração Pública pela Universidade Federal Fluminense (UFF), em 2014.

Foi eleita vereadora do Rio de Janeiro, em 2016, e sua campanha foi formada mediante o debate de três pilares: gênero, raça e cidade, envolvendo questões do lugar das mulheres na favela, da vulnerabilidade e violência deste espaço1o.

Recém-empossada no cargo, Marielle realiza seu primeiro discurso na Câmara no dia 15 de fevereiro de 2017, em Sessão Ordinária11. Em sua primeira fala cita a filosofia de origem africana Ubuntu 'eu sou porque nós somos', somos inclusive nas diferenças”, referindo-se que o Parlamento tem questões afins e divergentes e a tribuna será utilizada para defesa das questões que a elegeu. O mandato de Marielle é construído coletivamente, "temos lado, temos classe e identificação de gênero e ser a quinta vereadora mais votada é resposta e autorização da sociedade na representação", disse ela. Ainda reforçou e denunciou o emprego de não-técnicos em cargos da Prefeitura, nomeados pelo Prefeito Crivella, como o de Paulo César Amendola, exagente da Ditadura Militar, na função de Secretário de Ordem Pública12. "A Segurança Pública deve ser enfrentada pela Casa de modo preventivo (...) são relatos diários de vítimas, tanto de policiais da UPP como de moradores", disse ela ao contar sobre o tiroteio que já durava duas semanas no Morro do Alemão. A vereadora finalizou seu discurso mencionando sobre os projetos de lei que iniciam o mandato, um deles é o projeto "Espaço Coruja" (PL 017/2017) - autoria conjunta com o Vereador Tarcisio Motta - é um programa de espaço infantil noturno de atendimento à primeira infância, uma política pública voltada aos 
direitos sociais, cujo objetivo "é criar espaços noturnos para o cuidado com as crianças, por motivo de trabalho ou estudo da família" (Relatório Comissão da Mulher, p. 28). Registra-se que o projeto foi aprovado pela Câmara de Vereadores em agosto de 2018, Lei 6.419/201813.

Marielle fazia questão de ocupar a tribuna, principalmente no Dia Internacional da Mulher, reafirmando seu lugar de fala enquanto vereadora. Anunciava as ações conquistadas, as propostas encaminhadas e marcava a pauta sobre as diversas formas de violências que afetam as mulheres.

Em 2017 se referiu nominalmente a algumas das inúmeras vítimas, lembrou de Cláudia, mulher que foi assassinada e arrastada por Policiais Militares no Morro do Congonha; de Jandira, morta em razão de um aborto clandestino; de Dandara, travesti torturada, recebeu dois tiros e uma pedrada na cabeça; da Beth, esposa de Amarildo "desaparecido" pela Polícia Militar; de Elisa Samúdio, que ainda está "sumida"; de Dona Penha, retirada de sua casa, na Vila Autódromo, pela Prefeitura do Rio de forma violenta no dia o8 de março de 2016. Ainda frisou que a Reforma da Previdência, em âmbito nacional, quer tratar as mulheres de forma igualitária aos homens, mas desconsidera que, além das horas laborais habituais, todo o serviço doméstico é realizado, majoritariamente, por elas. E, ainda conforme dados, as mulheres negras, que ocupam a base da pirâmide socioeconômica, representam $61 \%$ das mulheres que exercem a atividade doméstica como trabalho, recebendo menores salários se comparar com as brancas.

Em 201814 ela iniciou com uma frase de ordem para a vida das mulheres em meio à crise em que o país se encontrava "que possamos viver com respeito a todas, cada uma com seus corpos, cada uma a sua maneira, cada uma na sua forma de resistência diária”. Ela pergunta como uma forma de reflexão: "O que é ser mulher? O que cada uma de nós deixamos de fazer ou fizemos com alguma dificuldade pela identidade de gênero, pelo fato de ser mulher?". É mês de luta, ela continua, "uma luta pelos direitos das mulheres, à vida dessas mulheres, uma luta por uma vida digna. Um dia de luta em que nós, mulheres, ocupamos mais uma vez a Tribuna”. Marielle ressalta a importância de ocupar aquele lugar no Poder Legislativo carioca fazendo resistência às reformas da previdência, contra o governo do então Prefeito, Marcelo Crivella, contra a intervenção federal no Rio de Janeiro, e ainda

ocupar este lugar, neste dia, com a luta pelos direitos, reforça o simbólico e o objetivo da luta das mulheres. (...) É uma luta pelo fim de 
toda forma de opressão que se reflete no racismo, na misoginia, na luta contra o patriarcado (...) Em um cenário de instabilidade, crises, escândalos no parlamento... é fundamental falar das mulheres que lutam por uma outra forma de se fazer política no processo democrático. Onde estão as vagas nas creches, como prometido pelo prefeito Crivella? Onde estão os educadores/as que passaram no concurso? Onde ficam as crianças, neste período de intervenção? (Marielle Franco, Discurso na Tribuna, 08 março 2018)

Marielle falava das violências contra às mulheres, que segundo dados da OMS (Organização Mundial de Saúde), o Brasil, dentre 73 países, ocupa a sétima posição de mais violento. No Rio de Janeiro, os últimos dados coletados mostram que há 13 estupros de mulheres por dia. É neste momento que Marielle é interrompida por um cidadão que estava presente e se pronunciou favoravelmente à Ditadura Militar (é possível ouvir um "viva Ustra" ao fundo do vídeo, aos 7:24'). Marielle escuta e pede à Presidência da Câmara que em caso de outras manifestações que atrapalhem sua fala, que proceda como faz quando a tribuna interrompe qualquer vereador, e ainda frisa que "não serei interrompida, não aturo interrupmento (sic) de vereadores da casa, não aturarei a interrupção de um cidadão que não sabe ouvir a posição de uma mulher, eleita, Presidente da Comissão da Mulher nessa Casa”. Ao continuar sua fala, Marielle diz que, as mulheres oriundas das favelas são violadas e violentadas há tempos, exemplifica com o período de intervenção federal que se concretiza na intervenção militar, questiona com ficam as mães e familiares das crianças revistadas quando vão à escola; como ficam as médicas que não podem trabalhar nos postos de saúde e as mulheres que ficam "isoladas" pelo não acesso à cidade. "Nossos corpos não são objetos como no período da escravização, estamos no processo democrático (...) vai ter que aturar mulher negra, trans, lésbica ocupando a diversidade dos espaços", disse Marielle.

Em entrevista15, realizada em fevereiro de 2018, fica nítido como a questão sobre segurança pública e democracia é estimada para Marielle. Nessa entrevista, ela ressalta que a nossa democracia está ameaçada, fazendo referência a mais uma intervenção federal "após os quatorze meses de incursão militar, não só da polícia militar, mas, também, da Força Nacional na Maré, ainda é latente o barulho do tanque. Esse medo, esse desespero é hora que a gente chora, por que corta na nossa carne", disse Marielle. Ainda pontua que mesmo havendo ameaças às vidas, há, também, resistências. Além de sua fala, também analiso sua atuação no cargo de Presidência da Comissão da Defesa da 
Mulher16 a partir do Relatório da Comissão de Defesa da Mulher da Câmara Municipal do Rio de Janeiro 2017 - 201817.

Marielle conquista a Presidência da Comissão, em fevereiro de 2017, ao lado das vereadoras, Verônica Costa, como Vice-Presidente e Rosa Fernandes, como Vogal. Destacarei algumas ações e projetos, como o Projeto de Lei (PL 016/2017), autoria de Marielle, que é um programa de atenção humanizada ao aborto legal e judicialmente autorizado no âmbito do Município do Rio de Janeiro - última movimentação foi em agosto de 2017, aguardando pareceres de Comissões18. Uma das justificativas pela proposição do projeto, segundo a Comissão, é em razão do "enfrentamento à mortalidade materna na cidade do Rio de Janeiro (....) Em meio às causas mais comuns podemos encontrar a infecção, muitas vezes ocasionada pela interrupção de gestação de forma insegura" (Relatório, p. 9).

Para enfrentar o tema de violência contra a mulher, a Comissão apresentou o Projeto de Lei "Assédio não é passageiro" (PL 417/2017), apresentado em setembro de 2017 e também de autoria de Marielle. É uma campanha permanente de conscientização e enfrentamento ao assédio e violência sexual em espaços públicos e transportes coletivos, na cidade do Rio. Foi aprovado pela Câmara em agosto de 2018, tonando-se a Lei 6.415/201819. Outra ação realizada por ela foi a Audiência Pública de Violência Sexual e Saúde da Mulher, ocorrida em setembro de 2017. Naquela oportunidade destacou as "informações, atendimentos e serviços garantidos por lei para mulheres vítimas de violência sexual" (Relatório, p. 20). Com o objetivo de manter informações e dados de violência contra a mulher para propor Políticas Públicas2o mais específicas e eficazes, foi apresentado o Projeto de Lei "Dossiê Mulher Carioca" (PL 555/2017), autoria de Marielle, e segundo a Comissão, "o documento consistirá na elaboração de estatísticas periódicas sobre políticas públicas municipais que atinjam as mulheres no município, devendo ser publicado anualmente" (Relatório, p. 21). Este projeto também foi aprovado, Lei no 6.394/201821.

Relativo à Segurança Pública, Marielle acompanhou algumas iniciativas no combate à violência estatal, como exemplo "a Frente Estadual pelo Desencarceramento; o Grupo de Trabalho Meninas e Mulheres Encarceradas do Comitê Estadual de Prevenção e Combate à Tortura de Meninas; e a pauta da Redução da Maioridade Penal" (Relatório, p. 22). Também foi apresentado o projeto (PL 515/2017) - autoria conjunta dos vereadores Marielle Franco, Tarcísio 
Motta, Leonel Brizola Neto e Prof. Célio Lupparelli - que institui o Programa de Efetivação de Medidas Socioeducativas em Meio Aberto no Município, como o objetivo de garantir a formação dos adolescentes, criar oportunidades de ingresso no mercado de trabalho, dentre outros. O projeto também foi aprovado em 2018, convertendo-se na Lei $6.416 / 201822$.

Já em relação à diversidade sexual e de gênero, algumas ações também foram realizadas pela Comissão, uma delas foi a efetivação do primeiro uso de crachá e carteira funcional com respeito ao nome social da história da Câmara, concedido à Lana de Holanda, assessora parlamentar do mandato de Marielle e mulher transgênero. Outra ação foi a homenagem no Dia Internacional da Mulher de 2017, com a entrega da Medalha Chiquinha Gonzaga, para a Prof ${ }^{\mathrm{a}}$. Doutora do Instituto Federal do Rio de Janeiro, Jaqueline Gomes de Jesus, mulher, negra e transsexual. Também foi proposto o projeto de Lei (PL 103/2017) - que incluiu o Dia de Tereza de Benguela e da Mulher Negra no calendário oficial do Município - que foi aprovado, Lei $n^{0} 6389 / 2018$, data que passa a ser comemorada em 25 de julho.

Como já salientado, o tema da Segurança Pública também era de extrema importância tanto para Marielle quanto para a sociedade do Rio de Janeiro, cidade que ela representava como ocupante do poder legislativo municipal. Ela compreendia que a segurança pública, para além de ser uma política pública, que deve ser adotada pela Administração Pública, "deve ser considerada como o resultado da articulação de diversas políticas sociais, visando a defesa de direitos, garantia e promoção da liberdade (...) principalmente porque segurança pública é muito mais que ação da polícia” (FRANCO, 2014, p. 24). Marielle discutiu esta temática, em sua dissertação de mestrado, intitulada como "UPP - A REDUÇÃO DA FAVELA A TRÊS LETRAS: uma análise da política de segurança pública do estado do Rio de Janeiro", cujo objetivo geral era "demonstrar que as Unidades de Polícia Pacificadora (UPPs), enquanto política de segurança pública adotada no estado do Rio de Janeiro, reforçam o modelo de Estado Penal, absolutamente integrado ao projeto neoliberal" (FRANCO, 2014, p. 15). Analisou a cidade que está em disputa, de um lado uma cidade focada no mercado e adepta a higienização urbana e, de outro, uma alternativa que rompesse com os padrões hegemônicos, "um projeto de cidade de direitos”. (FRANCO, 2014, p. 15). 
Ao analisar as UPPs, a autora verificou divergência de informação quanto a instalação desta política na favela da Maré, "não há decreto, ou legislação estadual, apenas a Garantia da Lei e da Ordem (GLO), que regulamenta a intervenção política e de polícia na Maré, porém, esta é apresentada como uma das UPP” (FRANCO, 2014, p. 53). No entanto, em outras comunidades, há decreto regulamentando sua implementação, baseando-se em um modelo de "pacificação". Ela ainda ressalta que há controvérsia se seriam uma unidade pacificadora, devido a várias denúncias de violações por parte das UPPs, como a entrada em domicílios sem mandados, abusos de autoridade, o "desaparecimento" de Amarildo de Souza23, dentre outros "Amarildos". A autora relembra que na Ditadura Militar a "Medalha de Bronze do Pacificador", era entregue a oficiais que se destacavam no combate aos guerrilheiros (leiase, militantes e organizações de esquerda24). "Pacificador" também era o nome atribuído ao veículo blindado da Coordenadoria de Recursos Especiais da Polícia Civil (CORE), porém, para os moradores das comunidades, o veículo era mais conhecido como "passa e fica a dor" ou "caveirão", o que demonstra um processo de militarização das favelas (FRANCO, 2014, p. 94-95).

Segundo Marielle,

as marcas dos homicídios não estão presentes apenas nas pesquisas, nos números, nos indicadores. Elas estão presentes sobretudo no peito de cada mãe de morador de favela ou mãe de policial que tenha perdido a vida. Nenhuma desculpa pública, seja governamental ou não, oficial ou não, é capaz de acalentar as mães que perderam seus filhos. (...) A $15^{\mathrm{a}}$ UPP Coroa-Fallet-Fogueteiro é marcada pela história de um policial atingido por uma granada e pela morte de um jovem, ainda no seu segundo ano de "pacificação". Não há como hierarquizar a dor, ou acreditar que apenas será doído para as mães de jovens favelados. O Estado bélico e militarizado é responsável pela dor que paira também nas 16 famílias dos policiais mortos desde o início das UPPs. (FRANCO, 2014, p. 99)

A autora evidencia, caminhando para conclusão de sua dissertação, que devem ser construídas alternativas que evitem o uso da força desproporcional e a violação de direitos dos cidadãos pelo Estado, uma delas seria a desmilitarização da polícia e a extinção de armamentos bélicos para enfrentar a população. Marielle defende, quanto a este ponto, a aprovação da PEC 51 - que apresenta uma nova configuração da polícia (FRANCO, 2014, p. 121). Além disso, destaca a importância de se criar "espaços de diálogo e decisão dos moradores; o respeito às 
regulações criadas pelos moradores nos espaços de favelas e periferias. Essas são ações que podem ser alteradas em nível estadual" (FRANCO, 2014, p. 110-111). Após análise da problemática, a autora conclui que

a política de Segurança Pública do Estado do Rio de Janeiro mantém as características de Estado Penal segundo Loic Wacquant. Os elementos centrais dessa constatação estão nas bases da ação militarizada da polícia, na repressão dos moradores, na inexistência da constituição de direitos e nas remoções para territórios periféricos da cidade (o que acontece em vários casos). Ou seja, a continuidade de uma lógica racista de ocupação dos presídios por negros e pobres, adicionada do elemento de descartar uma parte da população ao direito da cidade, continua marcando a segurança pública com o advento das UPPs. Elementos esses que são centrais para a relação entre Estado Penal e a polícia de segurança em curso no Rio de Janeiro (FRANCO, 2014, p. 126).

A dissertação de Marielle - que foi lançada como livro pela editora ( $\mathrm{N}-1)$ em novembro de 2018 - destaca e joga luz sobre um tema de extrema relevância e importância para a sociedade brasileira, principalmente para os grandes centros como Rio de Janeiro e São Paulo, que é sobre como a Segurança Pública pode ser "confundida" e efetuada com a atuação de um Estado policialesco, em que os abusos e violações de direitos são efetuados pelos agentes do Estado. E traz, como uma das alternativas ao combate desse Estado Penal, a questão da desmilitarização da polícia. Mas, após quatro anos de sua dissertação, em fevereiro de 2018, o Governo Federal, através do Decreto $\mathrm{n}^{0}$ 9. 288, instaura nova intervenção federal no Estado do Rio de Janeiro, com o objetivo de "pôr termo ao grave comprometimento da ordem pública".

Após conhecer um pouco mais sobre Marielle fica nítido que as questões que a transpassa assim como as que gravitam são questões que a constituiu enquanto sujeita. As questões de gênero, de raça, de classe, de sexo e territorial a marcam com várias identidades.

As questões nas quais Marielle acreditava, reivindicava, propunha e realizava, junto a colaboradores - como os projetos de Leis, eventos, encontros - refletem os problemas enfrentados em sua vida e que também atingem milhares de brasileiras e brasileiros que vivem à mercê do Estado. Como já dito, a vereadora se elegeu com a campanha "mulher, raça e cidade", a qual fez jus e obteve, até o momento, cinco Leis já publicadas, feito realizado em menos de dois anos de mandato. As propostas advêm sobre questões cotidianas que afetam, principalmente, 
mulheres faveladas, como elas vivem, onde vivem, quais as políticas públicas efetuadas no local, quais seus direitos violados. Essas diferenças devem ser vistas e tomadas como uma questão inseparável, parte de uma mesma estrutura, pois quando vista de modo separável não solucionam o problema apresentado, uma vez que mantêm uma visão apartada da sociedade e do sujeito, podendo, inclusive, reforçar a opressão.

\subsection{A violência sobre os corpos marcados}

A violência contra a mulher, segundo art. $1^{\mathrm{o}}$ da Convenção Interamericana para Prevenir, Punir e Erradicar a Violência Contra a Mulher - "Convenção de Belém do Pará”, de 1994, pode ser entendida como "qualquer ação ou conduta, baseada no gênero, que cause morte, dano ou sofrimento físico, sexual ou psicológico à mulher, tanto no âmbito público como no privado".25 O conceito de violência posto na Convenção é aberto, cerca os ambientes públicos e privados, abrange tanto a violência física, que marca o corpo, como a simbólica que causa dor na alma.

Entretanto, mesmo com as tentativas de prevenção, punição e erradicação da violência, desde a Delegacia da Mulher e em outros dispositivos como a Lei (Maria da Penha) 11.340/200626, é possível perceber o aumento da violência contra as mulheres27.

A disputa da relação de poder em que a violência simbólica opera - com aquele que sabe e que tem legitimidade para participar do espaço público e aquela outra que não sabe, ou, pelo menos, não deveria saber, e é deslegitimada a participar da esfera pública - gera uma relação de enfrentamentos que apresentam interesses conflitantes. Quando uma mulher sabe, tem conhecimento e fala, quando ela faz "ressoar o eco da vida-liberdade", como diz Conceição Evaristo, tornando-a visível, produz efeitos negativos, principalmente nos homens, pois não estão prontos a aceitarem e verem mulheres frequentando o mesmo espaço que eles. Isso gera um grande incômodo, pois a relação de dominação do homem para com a mulher é intensa e necessita da afirmação constante da superioridade masculina, sendo esta equação reafirmada pela doxa,"uma imaginação irrefletida do mundo que nos parece natural e autoevidente pelo fato de ter sido incutida em nós por processos de socialização" (ROCHA, 2009).

E, são nos espaços públicos de discussão que Djamila Ribeiro (2017) indaga "quem se importa com a nossa voz?” A autora - neste 
ponto ressalta a questão do gênero e da raça - relata a dificuldade da pessoa branca em ouvir, por conta do incômodo que as vozes silenciadas trazem, do confronto que é gerado quando se rompe com a voz única, uma vez que as narrativas daquelas que foram forçadas ao lugar do Outro, serão narrativas que visam trazer conflitos necessários para a mudança. "O não ouvir é a tendência a permanecer em um lugar cômodo e confortável daquele que se intitula poder falar sobre os Outros, enquanto esses Outros permanecem silenciados." (RIBEIRO, 2017, paginação irregular). Ainda acrescenta que essa não-escuta pode estar conectada com o fato do interlocutor em não querer assumir a verdade, ou reconhecer a opressão imposta, deslegitimando ou diminuindo o falante.

Marielle era uma dessas mulheres que sabiam, tinha conhecimento, que falava e lutava pelos direitos das mulheres, pelos direitos dos pobres, pelos direitos de todos os humanos. Recordo que uma forma de violência contra a mulher é a tentativa de excluí-la das exclusões materiais, culturais, intersubjetivas e existenciais e o silenciamento imposto a elas ocorre pelo fato delas não possuírem o mesmo status de igual parceira na sociedade, ou seja, as mulheres não dispõem da mesma paridade participativa conferida aos homens, elas não são reconhecidas reciprocamente como membras da sociedade devido aos "padrões institucionalizados de valor cultural", para utilizar $\mathrm{o}$ termo de Nancy Fraser (2002). Renegam às mulheres o poder de fala $\mathrm{e}$ quando isso ocorre, diz Djamila Ribeiro (2017), renegam também, a existência, pois o falar é um ato de existir. Então, se o falar é conferir existência, o calar é reverter a situação, é negar, é excluir. Silenciaram, mataram uma mulher, negra, de esquerda, feminista, mãe, lésbica, favelada e vereadora.

Infelizmente, no mesmo ano de sua morte, há um novo silenciamento para com Marielle. $\mathrm{O}$ fato ocorreu quando a placa que levava seu nome em uma praça do Rio de Janeiro, como forma de homenagem realizada pelo PSOL, foi quebrada por deputados eleitos pelo PSL28 (Daniel Silveira eleito deputado federal e Rodrigo Amorim29, eleito deputado estadual) em comício de Wilson Witzel (PSC - Partido Social Cristão), presente no fato, e também eleito governador do Rio de Janeiro. Parte da fala do deputado Amorim no comício - "se eu chegar na Alerj, eu vou decapitar esses vagabundos de PCdoB, PT e PSOL. Se o Daniel chegar em Brasília, ele vai varrer esses vagabundos e a gente vai tomar o poder nessa prefeitura e vai pintar Petrópolis de verde 
e amarelo"3o - demonstra a violência e o ódio propagado para com pessoas que pensam, agem, posicionam e propõem políticas sobre a ótica de outro espectro diferente do deles. O respeito deve ser concedido a todas as pessoas e não somente aos que pensam semelhante a mim, respeitar candidatos, políticos, debater com uma pluralidade de ideias e soluções para que o Brasil se desenvolva, diminua a desigualdade social, etc. faz parte das regras e do jogo político-democrático, ao contrário de um regime ditatorial que impõe o pensamento único.

Se há algo que deveríamos apreender de uma vez por todas é: não há esquecimento quando sujeitos sentem-se violados por práticas sistemáticas de violência estatal e de bloqueio da liberdade socialmente reconhecida. Se há algo que a história nos ensina é: os mortos nunca se calam. Aqueles cujos nomes o poder procurou anular sempre voltam com a força irredutível dos espectros. (SAFATLE, 2010, p. 252)

O corpo de Marielle foi calado, mas não o seu nome nem a sua memória, seu eco circunda mundo afora. Em dezembro de 2018, após aprovação do Projeto de Resolução $\mathrm{n}^{0}$ 15/2018, proposto por algumas vereadoras31, a tribuna da Câmara de vereadores do Rio de Janeiro ganhou o nome da vereadora Marielle Franco, em 2018, que foi homenageada com uma placa com os dizeres "Não serei interrompida. Não calarão a minha voz", frase dita por ela enquanto discursava no dia Internacional da Mulher, seis dias antes de ser executada. Também foi homenageada e lembrada em vários eventos, inclusive estrangeiros32.

Marielle vive, agora como um símbolo. Um símbolo que representa diversas lutas, das mulheres, das pretas, das faveladas, da resistência, dos Direitos Humanos, dos LGBT+. Um símbolo que dizia que temos que lutar pelo que nos une. Marielle, tristemente, entrou para as estatísticas de vítimas de homicídio. Considero, entretanto, que ela foi vítima de "uma morte política".

\subsection{A interseccionalidade em Marielle, presente}

Há, no espaço teórico e político, várias abordagens sobre feminismos, tais como liberal, radical, marxista, decolonial, negro, etc. e, que, para fins didáticos, são separados em fases/ondas/marés. A fase que me interessa, neste ponto, é a segunda, pois, é a partir de uma tensão entre o feminismo e o liberalismo, ocorrida na primeira fase, principalmente com relação à liberdade e autonomia, questionando a 
quem, de fato, os direitos são concedidos. Se as mulheres burguesas eram excluídas da condição de cidadãs, as mulheres pretas nem direito à condição de ser humana possuíam. Surge, então, a partir das críticas realizas pelas feministas sociais, marxistas e, principalmente, negras, uma reivindicação de como essas desigualdades e discriminações sociais violam a justiça. Patricia Hill Collins, em um ensaio que retrata as mudanças do feminismo negro e interseccional, relata que, no século XX, os trabalhos de,

June Jordan, assim como no de Angela Davis, Toni Cade Bambara, Shirley Chisholm, Alice Walker, Audre Lorde e outras feministas negras do período, pode-se encontrar uma declaração forte e precoce sobre interseccionalidade, em que a "liberdade é indivisível", tanto intelectualmente quando nas múltiplas lutas política. (COLLINS, 2017, p. 7)

Neste escrito, a autora frisa que a luta política não focava somente na questão da liberdade, mas também na relação entre justiça social, solidariedade, emancipação e democracia participativa. No entanto, quando as ativistas levam este conceito para a academia, algumas ideias foram assimiladas enquanto outras não, sendo comum a narrativa atual não relacionar a questão da interseccionalidade com o movimento político das feministas negras estadunidenses nas décadas de 60 e 70 (COLLINS, 2017, p. 7 - 8). O coletivo Combahee River, formado por mulheres afro-americanas publicou um documento, em 1995, dizendo que todas as formas de opressão deveriam ser interconectadas, mas este coletivo não estava sozinho. Somavam as mulheres latinas, indígenas, asiáticas que também enfrentavam tais opressões cotidianamente (COLLINS, 2017, p. 8).

Academicamente, a autora Kimberlé Crenshaw ficou conhecida como a intelectual que protagonizou o termo interseccionalidade, com a publicação do artigo "Mapeando as margens: interseccionalidade, políticas de identidade e violência contra mulheres não-brancas”, em 1991, mas, isso coloca na sombra várias mulheres ativistas e intelectuais que contribuíram para formar o pensamento de Crenshaw (COLLINS, 2017, p. 10 - 11). Ainda segundo Collins,

Crenshaw se baseia nas ideias de Combahee não só para nomear a interseccionalidade, mas também para (1) estabelecer relações entre identidade individual e identidade coletiva; (2) manter o foco nas estruturas sociais; (3) teorizar a partir da base (em de um modelo topdown) casos de violência contra mulheres de cor como um conjunto de 
experiências com conexões estruturais, políticas e representativas; (4) lembrar leitoras que o propósito dos estudos interseccionais é contribuir com iniciativas de justiça social. Crenshaw é clara está claramente defendendo a interseccionalidade como uma construção de justiça social, e não como uma teoria da verdade desvinculada das preocupações de justiça social. No entanto, esse aspecto do trabalho de Crenshaw tem sido cada vez mais negligenciado. (COLLINS, 2017, p. 12)

Nas palavras de Kimberlé Crenshaw:

discriminação interseccional é particularmente difícil de ser identificada em contextos onde forças econômicas, culturais e sociais silenciosamente moldam o pano de fundo, de forma a colocar as mulheres em uma posição onde acabam sendo afetadas por outros sistemas de subordinação. Por ser tão comum, a ponto de parecer um fato da vida, natural ou pelo menos imutável, esse pano de fundo (estrutural) é, muitas vezes, invisível. O efeito disso é que somente o aspecto mais imediato da discriminação é percebido, enquanto que a estrutura que coloca as mulheres na posição de receber tal subordinação permanece obscurecida. Como resultado, a discriminação em questão poderia ser vista simplesmente como sexista (se existir uma estrutura racial como pano de fundo) ou racista (se existir uma estrutura de gênero como pano de fundo). Para apreender a discriminação como um problema interseccional, as dimensões raciais ou de gênero, que são parte da estrutura, teriam de ser colocadas em primeiro plano, como fatores que contribuem para a produção da subordinação.(CRENSHAW, 2002, p. 176)

Consoante às ideias descritas o fato consequente às reivindicações realizadas nesta segunda onda do feminismo, como relata Fraser, é a ampliação do,

número de eixos que poderiam abrigar a injustiça. Rejeitando a primazia das classes, as feministas socialistas, as feministas negras e as feministas anti-imperialistas também se opuseram aos esforços de feministas radicais em situar o gênero naquela mesma posição de privilégio categorial. Focando não apenas no gênero, mas também na classe, na raça, na sexualidade e na nacionalidade, elas foram precursoras de uma alternativa "interseccionista" que é amplamente aceita. (...) As feministas discutiram, é claro, sobre como melhor caracterizar a totalidade social (...) em minha própria visão preferida, como uma forma historicamente específica, a sociedade capitalista organizada pelo Estado de forma androcêntrica, estruturada por três ordens inter-relacionadas de subordinação: (má) distribuição, (falta de) reconhecimento e (falta de) representação. (FRASER, 2009 p. 18) 
Isto posto, contrária à negligência indicada por Collins, é principalmente o último ponto, a interseccionalidade como uma construção de justiça social, que me fez utilizar o conceito de interseccionalidade apresentado por Crenshaw, uma vez que, adicionado à teoria fraseana de justiça social que possui um núcleo normativo de paridade participativa, permite ampliar o combate às injustiças sociais. Em resumo, este conceito permite olhar para as estruturas sociais que subordinam aqueles que são vítimas pelas múltiplas formas de injustiças que se perpassam mutuamente e, segundo Fraser (2001, p. 281), assim que as injustiças são percebidas, deve-se pensar em formas cruzadas de justiça redistributiva/reconhecimento/[representação]33, uma vez que a intersecção entre raça, gênero, classe, sexualidade, etc. reforça "a necessidade de soluções transformativas" (FRASER, 2001, p. 281).

Para Crenshaw, a discriminação interseccional pode ocorrer de forma mista ou composta ou como uma subordinação estrutural. A primeira "trata-se da combinação entre a discriminação racial e a discriminação de gênero. Portanto, as mulheres negras são afetadas, de maneira específica, pela combinação dessas duas formas diferentes de discriminação" (CRENSHAW, 2002, p. 13). Já na segunda não há um discriminador ativo pois não haveria uma discriminação destinada a um determinado grupo. No entanto, explica a autora que alguns fatores tais como políticas de ajustes - desvalorização do salário, redução de empregos, etc. - atingem as mulheres de modo mais negativo, geralmente forçando-as a absorverem os serviços que envolvem cuidado. E ainda, com a desigualdade socioeconômica existente entre as mulheres - pois a mulher negra está na base da pirâmide salarial - há uma marginalização socioeconômica. Essas mulheres marginalizadas expendem muito tempo para cuidar de suas famílias e das famílias de suas "patroas". Em síntese, subordinação estrutural, para a autora "é a confluência entre gênero, classe, globalização e raça”(CRENSHAW, 2001, p. 14).

Neste sentido, enquanto mulher e negra, Marielle também estava atravessada por outros marcadores, ou eixos de subordinação, como a classe e o sexo. Apresentava-se publicamente como "mulher, preta, favelada, lésbica”. Várias identidades em uma só pessoa, a "interseccionalidade permite às feministas criticidade política a fim de compreenderem a fluidez das identidades subalternas impostas a preconceitos, subordinações de gênero, de classe e raça e às opressões estruturais da matriz colonial moderna de onde saem" (AKOTIRENE, 
2018, p. 33). Em outras palavras, este olhar interseccional confere visibilidade às diferenças que muitas vezes são invisíveis ou naturalizadas, numa tentativa de romper com os padrões hegemônicos que marcam a masculinidade das interações e estruturas sociais.

A partir de um olhar interseccional e de todo descrito sobre Marielle e por suas marcações, é possível afirmar que ela foi vítima de ambas discriminações. A subordinação estrutural34 afetou Marielle pelo fato dela ser "cria da Maré". Ser da Periferia significa nascer, crescer e viver em um território apartado da sociedade, que é pobre, que é o gueto, é a "favela de marginais", local em que o Estado emprega poucas políticas públicas - a falta de creche, por exemplo, o que me faz recordar de quando Marielle engravidou na adolescência, aos 18 anos, tendo que deixar os estudos no pré-vestibular para cuidar da filha, ficando à mercê de políticas públicas não impostas pelo Estado. Ser da favela é pertencer a um lugar em que não há segurança pública, onde a polícia, em confronto com os "traficantes", para "assegurar a lei e a ordem" e "pacificar o território", mata e morre.

Marielle também foi vítima da discriminação mista ou composta. Enquanto discursava na Tribuna da Câmara, no dia o8 de março de 2018, em celebração ao Dia Internacional da Mulher quando falava dos últimos dados coletados sobre estupro, relembrando que à época eram 13 estupros de mulheres por dia na cidade do Rio de Janeiro. É neste momento que Marielle é interrompida por um cidadão que estava presente e se pronunciou favoravelmente à Ditadura Militar, gritou "viva Ustra”. Além disso, a interrupção de sua fala pode ser vista como uma tentativa de silenciamento imposta pela dominação masculina, pois foi realizada por um homem e em espaço público que tenta remeter à condição subalterna da mulher construída historicamente, que deve exercer atividades domésticas e em local privado, sendo renegada da esfera pública. Deste modo, esta posição social subalterna concede às mulheres menos acesso à posição de poder e de controle de bens materiais. Estão mais sujeitas à violência e humilhação. Falar desse silenciamento também me mostrou que é importante falar de uma outra forma de silêncio que pode denotar um ato de resistência. Esse ato pode ser percebido nesse momento em que Marielle discursava na tribuna, ao ser interrompida por um cidadão ela retoma a palavra e diz que não será interrompida e que não atura "interrupmento". A retomada de seu discurso, reafirmando a posição e o sentido original que era falar das várias violências que atingem várias mulheres pode ser considerado um 
ato de resistência, de resistir à tática da "política de silenciamento" que visa mudar o sentido do discurso.

\subsection{Que injustiça é essa?}

A discriminação interseccional descrita por Crenshaw pode ser compreendida em Nancy Fraser (2008, p. 118) como "padrões institucionalizados de valor cultural" que formam hierarquias institucionalizadas que impedem uma participação paritária e que violam a justiça quando atuam perante "o Outro" de forma que o inferioriza, o exclui e o ignora como parceiro da sociedade, podendo estar diante de uma "má-distribuição", de um "falso-reconhecimento" ou de uma "má-representação". Ou seja, a interação social é regulada por um padrão cisheteronormativo que normaliza e padroniza os indivíduos conforme tais normas, que inferioriza, oprime, marginaliza e silencia todos os outros que não estão neste padrão - negando-os o direito de participar paritariamente.

Depreendo, portanto, uma violação da justiça para com os corpos e as vozes de todas estas "Outras" que são deslegitimadas, subjugadas, silenciadas, excluídas, mortas, razão pela qual vejo a necessidade de reconhecer a mulher, enquanto sujeita legítima de direitos e igual parceira na sociedade.

Quando Fraser fala em reconhecimento recíproco, ela parte da perspectiva kantiana, de que o respeito é condição da humanidade e deve ser conferido universalmente a todos35, este fato me remete ao direito à voz que confere existência. Por conseguinte, posso concluir, ao menos por enquanto, que, ter o direito a falar a partir de seu local de pertencimento social é ser elevado à categoria de sujeito de direito, é ser reconhecido como um membro igual na sociedade. Portanto, "pensar lugar de fala seria romper com o silêncio instituído para quem foi subalternizado, um movimento no sentido de romper com a hierarquia" (RIBEIRO, 2017, paginação irregular). E essa hierarquia pode ser quebrada, rompida, mediante as vozes que se fazem presentes nas arenas de discussão, deliberação e que percebem o espaço social como uma construção e reprodução do sistema de gênero onde o lugar da mulher é construído, dentre outras possibilidades, como um lugar de subordinada, o que gera desigualdades de gênero, raça, classe/etnia, etc. violando a justiça social. 
Tendo em vista que as desigualdades podem ser usadas como meio de reprodução da dominação através dos discursos mantendo a marginalização das mulheres neste espaço, para que uma esfera pública seja capaz de incluir as mulheres com uma participação paritária, substancial, é necessário que "as desigualdades sociais sistêmicas sejam eliminadas (...) a democracia política requer uma igualdade social substantiva” (FRASER, 1992, p. 154)

Desta forma, uma resposta à exclusão realizada pelo público dominante e que ajuda a expandir o espaço discursivo parte de uma diversidade de públicos alternativos, os "contrapúblicos subalternos", local em que os grupos subordinados "criam e circulam contradiscursos para formular interpretações sobre seus interesses, identidades e necessidades" (FRASER, 1992, p. 156). Os contradiscursos devem incluir também assuntos que antes eram considerados privados, como a questão da violência contra a mulher e também permitir tanto a promoção de "públicos fracos", onde há somente a formação de opinião quanto de "públicos fortes", contemplando a formação de opinião e a tomada de decisão (FRASER, 1992, p. 169;172). Fraser, então, amplia seu escopo da justiça com uma nova gramática de reivindicação política, que também envolve a relação entre a representação simbólica e a representação como participação política (FRASER, 2009b, p. 15-16; p. 253), para isso ela abandona o enquadramento do estado nacional KeynesianoWestfaliano36, em que os atores da justiça não eram contestados, eram os cidadãos nacionais sendo "um poderoso instrumento de injustiça, que fraciona o espaço político de modo a beneficiar determinado grupo à custa dos pobres e desprezados" (FRASER, 2009b, p. 24).

Além disso, o que invalida a publicidade da democracia é a "a assimetria de poder, a ausência de paridade participativa entre os interlocutores" (FRASER et al, 2014, p. 147). Nesse caso, a aplicação do "princípio todo sujeito" serviria de base para a transnacionalizar a teoria crítica do século XXI, assegura a autora. Segundo esse princípio,

todos os que estão sujeitos a uma estrutura de governança, que define as regras básicas de sua interação, têm posição política em relação a esta estrutura. Em um nível, essa é uma questão objetiva, com certeza. Mas, diferentemente da condição objetiva da afetividade causal, a sujeição também carrega uma poderosa carga subjetiva, um conjunto de ressonâncias históricas que estampam experiências ofensivas em todo o espectro de múltiplas modernidades.(...) Apelando a todos que experimentam a sujeição, embora de maneiras diferentes e de acordo com diferentes temporalidades, tal teoria revela a base de contra- 
públicos subalternos em uma escala transnacional. Talvez também possa facilitar a formação de um bloco contra-hegemônico que busca uma transformação emancipatória da sociedade global. (FRASER et $a l, 2014$, p. 148-149, tradução minha)

Compreendo, então, que narrativas descritas a partir de experiências históricas de assujeições a uma determinada estrutura de governança injusta, não consentida, com assimetria de poder, revelaria a base para criar contradiscursos de resistência, ou seja, os contrapúblicos subalternos tanto ao norte quanto ao sul global, numa perspectiva transnacional. Neste sentido, "a ideia de que a sujeição confere o direito de participação serve para ampliar o escopo da publicidade democrática além das fronteiras do estado" (FRASER et al, 2014, p.150), o que evidencia que a cidadania não é o único requisito à participação.

É necessário, pois, promover uma multiplicidade das vozes para quebrar com o discurso autoritário e único, razão pela qual também se justifica o reconhecimento e reivindicação das vozes das mulheres na participação igualitária, nos espaços públicos de deliberação e tomada de decisão para que a visão universal cisheteronormativa (pautada pelo homem-branco-heterossexual-proprietário) seja rompida (RIBEIRO, 2017, paginação irregular). $\mathrm{O}$ ato de falar é uma ato de subverter à ordem posta.

E foi isso o que Marielle fez, mesmo enfrentando desigualdades, tanto a nível econômico, com escassez de recursos e bem materiais, quanto social e político. Quando é achincalhada por ser homossexual ou quando sua fala é interrompida, sendo impedida de participar como uma igual na sociedade, há uma subordinação de status ou falso reconhecimento. Já no campo político, enquanto vereadora reafirmando a necessidade de mais mulheres estarem neste espaço, influenciando e reordenando as fronteiras da comunidade a partir da criação de projetos de leis, programas e debates realizados dentro destas fronteiras que permanecem, ainda, apartada do centro - significava e apresentava para a sua comunidade da Maré, e para tantas outras, a tentativa de reparação da injustiça de uma má-representação que tais comunidades vivem por serem excluídas dos debates e por não terem oportunidades para expressarem politicamente suas reivindicações.

Marielle, com sua vivência e pensamento a partir da periferia, trouxe para o espaço político - um local caracteristicamente cisheteronormativo - mulheres negras para trabalharem de forma 
conjunta em sua "mandata" 37 , também, numa clara tentativa de mover as fronteiras do espaço público tradicional-nacional, questionando a ordem posta, mediante, inclusive, a internacionalização de sua morte política.

Deste modo, ao considerar uma visão transformativa da teoria freseana na questão da representação - que estabelece quem são os sujeitos da justiça social ou quem conta como membro legítimo à participação - pautada pelo princípio do todos-sujeitos, fica visível que a esfera pública e seus membros deve ser conferido segundo o alcance ou o limite das interações sociais a que estão submetidos, ou seja, se esta sujeição ultrapassa o Estado Nacional, deve-se adotar uma esfera pública transnacional (FRASER, 2008, p. 179).

\section{Considerações finais}

O pertencimento de Marielle à sua comunidade física, local, da Maré e sua constante afirmação de suas identidades, são questões que marcam o seu pertencimento à comunidade LGBTQ+, à feminista, à esquerda, comunidades, essas, que possuem reivindicações também a níveis transnacionais. A luta por justiça social convida pessoas diversas a ocuparem o espaço político, ainda que de forma indireta. A ocupação desse espaço que, historicamente, é ocupado por homens e brancos e passa a ser compartilhado com mulheres e negras, e que demonstram que estão lá para fazerem política, causa um grande incômodo nas estruturas e instituições tradicionais/conservadoras que desejam permanecer com o status quo.

Logo, o pertencimento de Marielle às suas diversas comunidades proporcionou que tais pessoas tivessem, minimamente, seus direitos garantidos, (vale lembrar das ações e projetos de lei aprovados em menos de 2 anos de mandato) pois ela estava representando os interesses e necessidades e que, essencialmente, eles fossem vistos como seres humanos - o seu compromisso de representação perante suas comunidades foi reafirmado em sua primeira fala na tribuna, dizendo que o mandato foi construído coletivamente, "temos lado, temos classe e identificação de gênero" (FRANCO, discurso na Alerj, fev. 2018)38. Ao reivindicar, em seu mandato, as questões relacionadas a sua campanha, sobre "mulher, raça e cidade", Marielle eleva seu status de igual parceira na sociedade e ao jogar luz sobre estas sujeitas, até então invisibilizadas, silenciadas e subalternizadas e sobre as questões que elas reivindicam, 
tentando elevá-las ao patamar de "iguais sujeitas" participantes da vida social, desencadeou o efeito do "falso reconhecimento reativo" 39 (FRASER, 2001, p. 270) que é uma prática estigmatizante que desrespeita os beneficiários [e também os defensores] de determinada política pública/leis. A reação gerada por esse falso reconhecimento é a tentativa de exclusão de tais benefícios e das reivindicações de justiça que elevem o status da sujeita na arena pública.

Assim, para Marielle voltar ao seu lugar de ser inferior, para não mais falar, para não mais reivindicar, para não mais incomodar, excluíram-na, executaram-na. Silenciaram, brutalmente, uma mulher que se colocou no espaço público com o objetivo de proporcionar melhores condições de vida, mais dignidade a outras mulheres que ocupavam e ocupam um território posto à margem pelo Estado. É por todo o exposto que correlaciono que Marielle foi vítima de uma injustiça de uma falsa representação, de mau enquadramento, considero, ainda, que sofreu uma injustiça mais severa que é a "morte política", pois foi excluída dos futuros debates sobre questões de justiça e do pertencimento a qualquer comunidade.

Para que uma política de representação se torne adequada "deve, além de contestar a falsa representação política-comum e o mau enquadramento, também procurar democratizar o processo de estabelecimento do enquadramento" (FRASER, 2009b, p. 26). Deste modo, a partir de um procedimento democrático, deve ocorrer uma mudança nos arranjos sociais para que várias vozes das mulheres, ou "subalternas", sejam incluídas nas deliberações, discussões e tomadas de decisão de diversas questões, inclusive na questão de como se constitui o espaço político, ou as fronteiras, do "quem", na linguagem freseana (FRASER, 2008, p. 134) quem, de fato, está subordinado a uma determinada estrutura de governança.

\section{Referências}

AKOTIRENE, Carla. O que é interseccionalidade? Belo Horizonte (MG): Letramento, 2018.

BOURDIEU, Pierre. A dominação masculina. Tradução Maria Helena Kühner. 11 ${ }^{\mathrm{a}}$ ed. Rio de Janeiro: Bertrand Brasil, 2012. 
COLLINS, Patricia Hill. Se perdeu na tradução? Feminismo negro, interseccionalidade e política emancipatória. Tradução: Bianca Santana. Revista Parágrafo. jan/jun. 2017, v.5, n.1 Disponível em: http://revistaseletronicas.fiamfaam.br/index.php/recicofi/article/view/ 559 Acesso abril 2019.

CRENSHAW, Kimberlé. A Intersecionalidade na Discriminação de Raça e Gênero. In: VV.AA. Cruzamento: raça e gênero. Brasília: Unifem, 2002. Disponível em <https://static.tumblr.com/7symefv/V6vmj45f5/ kimberle-crenshaw.pdf $>$. Acesso em janeiro 2019.

CRENSHAW, Kimberlé. Documento para encontro de especialistas em discriminação de gênero e racial. 2002. Disponível em <https:// www.scielo.br/pdf/ref/v10n1/11636.pdf>. Acesso em janeiro de 2019.

FRASER, Nancy. Escalas Justicia. S.L, Barcelona: Herder Editorial. 2008

FRASER, Nancy. Repensando la esfera pública: una contribución a la crítica de la democracia actualmente existente (Tema central). En: Ecuador Debate. Opinión pública. Quito: CAAP, (no. 46, abril 1999): pp. 139-174. ISSN: 1012-1498. Disponível em: <https:// repositorio.flacsoandes.edu.ec/handle/10469/5760 >. Acesso em agosto de 2018.

FRASER, Nancy. A justiça social na globalização: Redistribuição, reconhecimento e participação. Revista Crítica de Ciências Sociais [Online], 63 | 2002, colocado online no dia 01 Outubro 2012, criado a 29 Setembro 2016. URL : http://rccs.revues.org/1250 ; DOI : 10.4000/ rccs. 1250

FRASER, Nancy e HONNETH, Axel. Redistribuição ou reconhecimento? Um debate político-filosófico. Madrid: Morata S.L, 2006

FRASER, Nancy. O feminismo, o capitalismo e a astúcia da história. Revista Mediações, Londrina, v. 14, n.2, p. 11-33, Jul/Dez. 2009.

FRASER, Nancy et al. Edited by Kate Nash. Transnationalizing the Public Sphere. Ed (1 $\left.{ }^{\text {a }}\right)$ Polity Press, 2014

FRANCO, Marielle. (Dissertação). UPP - A REDUÇÃO DA FAVELA A TRÊS LETRAS: uma análise da política de segurança pública do estado 
do Rio de Janeiro. Universidade Feeral Fluminense (UFF). 2014. Disponível em <https://app.uff.br/riuff/bitstream/1/2166/1/ Marielle\%20Franco.pdf> Acesso em dezembro de 2018.

GUSTIN, Miracy Barbosa de Sousa; DIAS, Maria Tereza Fonseca. (Re)pensando a pesquisa jurídica: teoria e prática. $2^{\mathrm{a}}$ edição. Belo Horizonte(MG): Del Rey. 2002

ORLANDI. Eni Puccinelli. As formas do silêncio: no movimento dos sentidos. $6^{\mathrm{a}}$ ed. Campinas-SP: Unicamp, 2007.

RELATÓRIO da Comissão de Defesa da Mulher. Câmara Municipal do Rio de Janeiro, 2017 - 2018. Disponível em <https://drive.google.com/ file/d/1CGg6qxfRx8jUcqhO4ES32bd5r1eOok9i/view> Acesso em janeiro de 2019.

RIBEIRO, Djamila. O que é lugar de fala? Belo Horizonte (MG): Letramento, 2017. eBook.

ROCHA, Emerson. Cor e Dor Moral: sobre o racismo na "ralé". In: SOUZA, Jessé (org.). A Ralé Brasileira: quem é e como vive. Belo Horizonte: Editora UFMG, 2009, p. 353-383 (Capítulo 15)

SAFATLE, Vladimir. Do uso da violência contra o Estado ilegal In. O que resta da ditadura: a exceção brasileira/ Edson Teles e Vladimir Safatle (Orgs.). - São Paulo: Boitempo, 2010. 


\section{The Silencing of Marielle}

ABSTRACT: The aim of this article is to make an empirical-contextual narrative about the case of the murder of Councilwoman Marielle Franco from the content analysis of her speeches describing the public-political context, characteristics and relationships between the variables to reach the theoretical, using the legal-sociological method1. It is considered that the political field is historically male, white, bourgeois and excluding the voices of the "subordinates" and the choice of the case is justified by the motivation of the crime, since that murder means the silence of his voice. The research development context begins in 2017, in Brazil, the year the councilwoman assumed her mandate. The contribution of the Fraser concept (parity of participation) to the promotion of more dialogic and democratic spaces is analyzed through the recognition of subordinate subjects as equal participants in the social order.

KEYWORDS: Parity participation. Silencing women's voices. Intersectionality. Social injustice. Gender inequality.

Emely Braga RODRIGUES

Mestranda em Direito pelo programa de Pós-Gradução "Novos Direitos, Novos Sujeitos" da Universidade Federal de Ouro Preto/MG.

Recebido em: $31 / 12 / 2019$

Aprovado em: 12/10/2020 